\title{
Changes in hematocrit based on incremental blood sampling: mathematical models perform poorly
}

\author{
[Modifications de l'hématocrite fondées sur des échantillons sanguins incrémentiels: \\ piètre performance des modèles mathématiques]
}

Luis I. Cortinez MD, ${ }^{*}$ Jacques Somma MD FrCP(C), ${ }^{*}$ Kerri M. Robertson MD FrCP(C), John C. Keifer MD, David R. Wright BM FrCA, Yung-Wei Hsu MD, David B. MacLeod BM FRCA, Eugene W. Moretti MD

Purpose: Excessive blood sampling, with its inherent risks, is of growing concern among clinicians. We performed this study to measure the changes in hematocrit (Hct) during a laboratory investigation where multiple blood samples are collected. The performance of a simple mathematical model, used in clinical practice to predict Hct changes, is evaluated.

Methods: Eight healthy male volunteers participated in this study. The equation $\mathrm{Hct}_{\mathrm{f}}=\mathrm{Hct}_{\mathrm{i}}^{*}(\mathrm{EBV}-\mathrm{BL}) / \mathrm{EBV}$ is used to predict changes in Hct. Where $\mathrm{Hct}_{\mathrm{f}}$ and $\mathrm{Hct}$, are, respectively, the final and initial $\mathrm{Hct}, \mathrm{EBV}$ is the estimated blood volume and BL is the blood loss.

Results: Thirty-five pharmacokinetic samples per subject were collected totalling $314 \mathrm{~mL}$ of $\mathrm{BL}$.

The Hct decreased from $44.2 \% \pm 2.2 \%$ to $39.9 \% \pm 2.5 \%(P=$ $0.00 \mathrm{I})$. On average, model predictions tended to have a discrete tendency to underestimate the Hct changes (- $0.5 \%$ points of bias). While the predictions of the Hct were very accurate in $50 \%$ of the subjects, the discrepancy of the Hct predictions was clinically significant in the other $50 \%$ of the subjects.

Conclusion: Consistent with the model prediction, this study demonstrated a significant reduction in the Hct values in healthy subjects undergoing incremental phlebotomy. On average, the model successfully predicted the decrease in Hct. However, the inter- and intra-individual variabilities in the Hct changes are clinically significant. In clinical settings, which are not well controlled environments, the variability is likely to be greater and the clinical use of the model cannot replace the need to monitor the Hct.
Objectif : Les échantillons sanguins excessifs, et leurs risques inhérents, préoccupent de plus en plus les cliniciens. Nous avons mesuré les modifications de l'hématocrite (Hct) au cours d'une investigation en laboratoire où de multiples échantillons sanguins sont prélevés. La performance d'un modèle mathématique simple, qui prédit les changements de l'Hct en clinique, est évaluée.

Méthode : Huit hommes volontaires en santé ont participé à l'étude. L'équation Hct $\mathrm{HCt}_{f}=\mathrm{HCt}_{i}^{*}$ VSE-PS)NSE sert a prédire les changements de l'Hct où $\mathrm{Hct}_{f}$ et Hct, sont respectivement l'Hct final et initial, VSE est le volume sanguin estimé et PS est la perte sanguine.

Résultats : Trente-cinq échantillons pharmacocinétiques par sujet ont été prélevés pour un total de $314 \mathrm{~mL}$ de PS.

L'Hct a diminué de 44,2\% $\pm 2,2 \%$ à 39,9\% \pm 2,5\% ( $P=$ $0,001)$. Les prédictions du modèle présentaient en moyenne une tendance discrète à sous-estimer les modifications de l'Hct (-0,5\% de biais). Les prédictions de l'Hct ont été très exactes chez $50 \%$ des sujets, mais la divergence dans les prédictions était cliniquement significative chez les autres $50 \%$.

Conclusion : L'étude a démontré, conformément au modèle de prédiction, une réduction significative des valeurs de l'Hct chez des sujets sains qui subissent une phlébotomie incrémentielle. En moyenne, le modèle a pu prédire la baisse de l'Hct. Cependant, les variations interindividuelles et intra-individuelles de modification de l'Hct sont cliniquement significatives. En clinique, ce qui n'est pas un environnement bien contrôlé, la variabilité risque d'être plus grande et l'usage clinique du modèle ne peut remplacer la nécessité du moniteur d'Hct.

From the Department of Anesthesiology, Duke University Medical Center, Durham, North Carolina, USA.

Address correspondence to: Dr. Luis I. Cortínez, Departamento de Anestesiología, Hospital clínico, Pontificia Universidad Católica de

Chile, Marcoleta 367, Santiago, Chile. Phone: 562-6863270; Fax: 562-6327620; E-mail: licorti@med.puc.cl

${ }^{*}$ Both authors contributed equally to this manuscript.

Funding: This study on dexmedetomidine vs remifentanil was funded by Abbott Laboratories (Abbott Park, Illinois, USA). Accepted for publication August 10, 2004.

Revision accepted January 14, 2005. 
A NEMIA necessitating transfusion is a welldocumented complication of repeated phlebotomy for laboratory testing. ${ }^{1-4}$ However, decrements in hematocrit (Hct) associated with excessive blood sampling are difficult to investigate in the clinical population. These patients are often hospitalized in intensive care units (ICU) and have multiple potential bleeding sites and co-morbidities that might interfere with Hct changes. In contrast, very accurate estimations of blood loss (BL) in a relatively well-controlled environment are commonly present in healthy volunteer studies where blood samples constitute the only cause of bleeding. This type of study offers an excellent opportunity to explore the dynamic nature of Hct changes following repeated phlebotomies.

Different formulas derived from the original differential equation described by Bourke and Smith ${ }^{5}$ have widely been used to calculate changes in Hct according to BL. ${ }^{6,7}$ To our knowledge there are no prospective studies in the literature measuring the effects of incremental blood sampling on serial Hct in healthy volunteers. In addition, the performance of mathematical models in this scenario has not been assessed.

The objectives of this work are: 1) to describe the changes in Hct and its variability in healthy volunteers who had undergone a 24-hr laboratory investigation requiring multiple pharmacokinetic samples and 2) to assess the agreement between a simple mathematical model and measured Hct in this scenario.

\section{Material and methods}

After obtaining Instutional Review Board approval and informed consent, eight healthy ASA I male volunteers, 21 to $40 \mathrm{yr}$ of age, participated in a laboratory investigation assessing the analgesic and respiratory effects of remifentanil (REMI) and dexmedetomidine (DEX). This single-centre, double-blinded study consisted of three parts. During parts 1 and 2, the subjects received REMI or DEX via target control infusion (STANPUMP, Steven L. Shafer, Palo Alto, CA, USA). During part 3, no drugs were infused and the subjects were requested to sleep. The approximate starting times of parts 1, 2 and 3 were respectively 9:00 a.m., 1:00 p.m. and 10:00 p.m. Each study session lasted about $24 \mathrm{hr}$.

As per protocol design, subjects were kept npo after midnight the evening prior to participation. On the morning of the study, an 18-gauge $i v$ catheter was started in the non-dominant arm. A $5 \mathrm{~g} \cdot \mathrm{dL}^{-1}$ dextrose and $0.45 \% \mathrm{NaCl}$ in water solution was infused at a rate of $100 \mathrm{~mL} \cdot \mathrm{hr}^{-1}$ (for $10-12 \mathrm{hr}$ ) until completion of the second part of the study. Radial arterial cannulation was performed in the non-dominant hand for blood sampling.
Thirty-five pharmacokinetic blood samples were collected over the 24-hr period for a total of $314 \mathrm{~mL}$. On average, $58 \mathrm{Hct}$ and arterial blood gas samples were obtained by a VIAV-ABG-1 (VIA Medical Corporation $囚)$ at regular intervals during the three parts of the study. This automated blood gas analyzer removes a $2-\mathrm{mL}$ aliquot of the subject's blood from the indwelling arterial catheter, and returns it back to the subject, once the analysis is completed. Consequently, BL secondary to this sampling was considered negligible and not taken into account in the BL estimations. ${ }^{8,9}$

All subjects were given the opportunity to eat and drink ad libitum before starting the third part of the study. Of the total amount of blood drawn $(314 \mathrm{~mL})$, only $40 \mathrm{~mL}$ were collected during the third part of the study. At this point, all of them were alert and able to tolerate oral fluids. No drugs or iv fluids were infused during the night.

\section{Initial data analysis}

To minimize the effect of variability originating from the error of measurements, the initial and final Hct values were estimated as the average of the first five and final five Hct measurements. The absolute change in Hct was calculated for each subject. A 95\% confidence interval was calculated for the average change. Initial and final Hct values were compared using a paired Student t test. A $P$ value $<0.05$ was considered statistically significant. Statistical analyses (including the model analyses described below) were performed with Microsoft Excel 2000 ( and S-Plus 6.0 (Insightful Corp, Seattle, Washington, USA).

\section{Model analysis}

The analyses described in this study were based on equation 1. This equation describes the decrease in Hct as equal to the fraction of the total blood volume that has been lost.

$$
\mathrm{Hct}_{\mathrm{f}}=\mathrm{Hct}_{\mathrm{i}} * \frac{(\mathrm{EBV}-\mathrm{BL})}{\mathrm{EBV}}
$$

where, EBV = estimated blood volume, Hct $_{\mathrm{i}}=$ initial hematocrit, and $\mathrm{Hct}_{\mathrm{f}}=$ final hematocrit.

Individual $\mathrm{Hct}_{\mathrm{i}}$ and $\mathrm{EBV}$ values were used in equation $\mathrm{l}$ to estimate $\mathrm{Hct}_{\mathrm{f}}$ (predicted $\mathrm{Hct}$ ) according to the measured BL throughout the study. This approach mimics the way the equation is used in the clinical setting, and the predictions of the model are based only on the knowledge of the Hct at the start of the study. The EBV was estimated as $70 \mathrm{~mL} \cdot \mathrm{kg}^{-1}$. Measured and predicted Hct were plotted in function of BL. Diagnostic plots were constructed, which included a 
TABLE I Demographic characteristics

\begin{tabular}{lllll}
\hline Subject & $\begin{array}{l}\text { Age } \\
(y r)\end{array}$ & $\begin{array}{l}\text { Weight } \\
(\mathrm{kg})\end{array}$ & $\begin{array}{l}\text { Height } \\
(\mathrm{cm})\end{array}$ & $\begin{array}{l}\text { Body mass index } \\
\left(\mathrm{kg} \cdot \mathrm{m}^{2}\right)\end{array}$ \\
\hline 1 & 24 & 81 & 182 & 25 \\
2 & 24 & 64 & 165 & 23 \\
3 & 29 & 82 & 175 & 26 \\
4 & 26 & 62 & 168 & 22 \\
5 & 22 & 85 & 182 & 26 \\
6 & 30 & 82 & 178 & 26 \\
7 & 22 & 87 & 190 & 24 \\
8 & 23 & 75 & 192 & 21 \\
Mean & 25.0 & 77.3 & 179.0 & 24.1 \\
SD & 3.1 & 9.5 & 9.6 & 2.0 \\
\hline
\end{tabular}

TABLE II Initial and final Hct values

\begin{tabular}{lllll}
\hline Subject & $\begin{array}{l}H_{c t} \\
(\%)\end{array}$ & $\begin{array}{l}H_{i} t_{f} \\
(\%)\end{array}$ & $\begin{array}{l}\text { Observed } \\
(\% \text { points })\end{array}$ & $\begin{array}{l}\text { Predicted } \\
(\% \text { points })\end{array}$ \\
\hline 1 & 44.4 & 37.3 & 7.2 & 2.3 \\
2 & 46.6 & 45.0 & 1.6 & 3.1 \\
3 & 43.6 & 40.3 & 3.4 & 2.2 \\
4 & 47.0 & 39.3 & 7.8 & 3.3 \\
5 & 42.4 & 38.8 & 3.7 & 2.2 \\
6 & 45.0 & 42.0 & 3.0 & 2.2 \\
7 & 40.2 & 38.3 & 2.0 & 2.1 \\
8 & 44.0 & 38.3 & 5.8 & 2.4 \\
Mean & 44.2 & $39.9 *$ & 4.3 & 2.5 \\
SD & 2.2 & 2.5 & 2.3 & 0.5 \\
\hline
\end{tabular}

$\mathrm{Hct}=$ hematocrit; $\mathrm{Hct}_{\mathrm{i}}=$ initial hematocrit $\mathrm{Hct}_{\mathrm{f}}=$ final hematocrit; *Significant decrement in Hct $(P=0.001)$.

plot of the predicted Hct against the measured Htc and a plot of the residuals (measured - predicted Hct).

\section{Results}

\section{Initial analysis}

Demographic characteristics are shown in Table I. All of the subjects remained hemodynamically stable throughout the study. When the data of the eight subjects were pooled, a statistically significant decrease in the Hct values $(P=0.001)$ was observed between starting $(44.2 \% \pm 2.2 \%)$ and finishing $(39.9 \% \pm 2.5 \%)$ Hct values (Table II) .

\section{Model analysis}

The total absolute change in Hct, estimated by equation $1,(2.5 \%)$ tended to be smaller than the measured change $(4.3 \%) ;(P=0.06)$; (Table II). In two subjects the observed decrease in Hct $(7.2 \%$ and $7.8 \%)$ was about three times higher than what was predicted $(2.3 \%$ and $3.3 \%$ ); (Table II). Individual plots of the Hct (measured and predicted) in function of BL are found in Figure 1. A moderate correlation $(\mathrm{R}=0.44)$ is observed

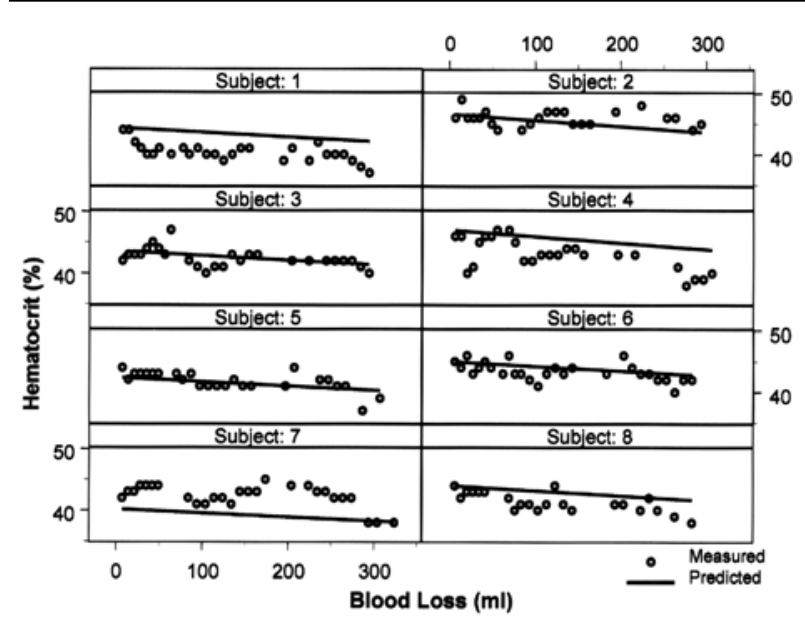

FIGURE 1 Measured and predicted hematocrit values throughout the 24 -hr study. Some subjects (\#3, \#5 and \#6) are very well predicted by the model, other subjects (\#1, \#4 and \#7) exhibit a significant discrepancy with it.

between the measured and predicted Hcts (Figure 2). The residual plot (Figure 3 ) shows a small bias $(-0.36 \%)$ and a relatively large variability with a standard deviation of $2.33 \%$. Ninety-five percent of the differences between the real Hcts and the model predictions lied between $-5 \%$ points and $4 \%$ points (Figure 3 ).

\section{Discussion}

This study demonstrated a significant reduction in the Hct in healthy subjects undergoing incremental phlebotomy. While the average reduction in the Hct is consistent with the prediction of equation 1 , there were significant differences between model predictions and measured Hct in some subjects $(95 \%$ of the differences between the real Hct and the model predictions lied between $-5 \%$ points and $4 \%$ points). These differences suggest that in a clinical setting equation 1 should not replace Hct measurements in patients subjected to incremental BL, especially in those patients with major end-organ disease or patients with low initial Hct values in whom there is less margin for error.

The results of our study showing that blood sampling produced a significant decrement in subjects' Hct is in agreement with clinical studies performed in ICU patients where phlebotomies have been shown to be a major factor contributing to anemia and red blood cell transfusions. ${ }^{4,10}$ In our study the amount of blood withdrawn per patient was on average $314 \mathrm{~mL}$ 


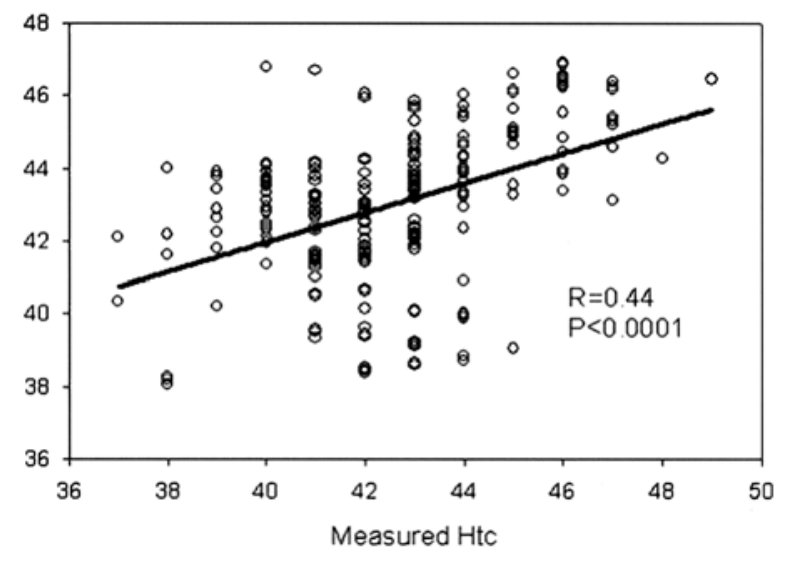

FIGURE 2 Correlation graphs between measured and predicted hematocrits.

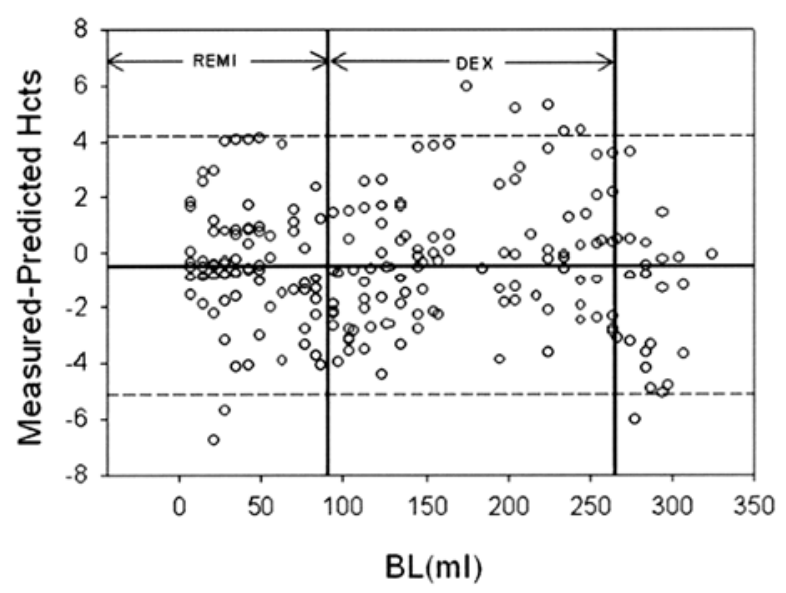

FIGURE 3 The residuals (measured - predicted hematocrits) are presented in function of blood loss (BL). Vertical solid lines divide remifentanil, dexmedetomidine and sleep parts of the study. Horizontal solid lines are the bias of the model (mean of the residuals). Dotted lines are the $95 \%$ confidence intervals.

during the 24-hr period. This amount of BL can be considered poorly relevant to the clinical setting. However, it has been shown that ICU patients are phlebotomized on average 40 to $70 \mathrm{~mL}$ per day and that BL in this range are associated with the development of anemia. ${ }^{10}$
It is unlikely that the differences between the values for starting and finishing Hct observed in our study could be accounted for, in part, by hemodilution. In our study the subjects received a D $5 \mathrm{~W} / 0.45 \% \mathrm{NaCl}$ solution at a rate of $100 \mathrm{~mL} \cdot \mathrm{hr}-1$ (for $10-12 \mathrm{hr}$ ). This infusion rate was calculated according to the metabolic water requirements and did not account for replacement of BL. ${ }^{11}$ In addition, a study by Hahn and Svensen, ${ }^{12}$ examining plasma dilution and the rate of infusion of lactated Ringer's solution, revealed the difficulty of obtaining hemodilution in healthy awake humans.

\section{Model analysis}

Our model analysis was based on equation 1 , which is virtually identical to the Bourke and Smith equation ${ }^{5}$ for $\mathrm{BL}<500 \mathrm{~mL}$. For example, the use of both equations in a scenario of a $\mathrm{Hct}_{\mathrm{i}}=40, \mathrm{EBV}=5 \mathrm{l}$ and a BL $=500 \mathrm{~mL}$ result in a difference of less than $0.2 \%$.

Clinicians typically use the starting Hct, $\mathrm{Hct}_{i}$, and the known or estimated BL to predict the $\mathrm{Hct}_{\mathrm{f}}$ according to equation 1 . With this approach, while some subjects' Hct (\#3, \#5 and \#6) are very well predicted by the model, other subjects' Hct (\#1, \#4 and \#7) exhibit a significant discrepancy with the model. The difference between measured and predicted Htcs results from both the intra- and inter-individual variability. The scaling of EBV using body weight is an attempt to reduce the inter-individual variability, however one cannot expect this approach to eliminate it completely. The inter-individual variability can be explained by differences among individuals such as different blood volumes ${ }^{13,14}$ or differences in the efficiency of compensatory mechanisms. On the other hand, the intra-individual variability originates from factors such as measurement errors [VIAV-ABG-1 (VIA Medical Corporation ${ }^{\circledR}$ ) performance], ${ }^{9}$ hemodilution or hemoconcentration, and under or overestimation of BL.

From our results it is clear that inter and intra-individual variations in the amount of Hct changes after blood sampling are large and very difficult to predict with the use of equation 1 . In clinical settings, which are not well controlled environments, the variability is likely to be greater than what was described in this manuscript, and the use of calculations cannot replace the regular monitoring of hemoglobin/Hct values.

\section{Conclusion}

In conclusion, this study demonstrated a significant reduction in the Hct in healthy subjects undergoing incremental phlebotomy. This study also demonstrated that model predictions of the Hct were very accu- 
rate in $50 \%$ of subjects but the discrepancy of the Hct predictions was clinically significant in the other $50 \%$ of subjects. In clinical settings, which are not well controlled environments, the variability is likely to be greater than what is described in this manuscript, and the clinical use of equation 1 cannot replace the need of monitoring the Hct of patients subjected to incremental BL.

\section{References}

1 Hicks JM. Excessive blood drawing for laboratory tests (Letter). N Engl J Med 1999; 340: 1690.

2 Sainato D. Do hospitals draw too much blood? Clin Lab News 1999; 25: 1-10.

3 Madsen LP, Rasmussen MK, Bjerregaard LL, Nobr SB, Ebbesen $F$. Impact of blood sampling in very preterm infants. Scand J Clin Lab Invest 2000; 60: 125-32.

4 Smoller BR, Kruskall MS. Phlebotomy for diagnostic laboratory tests in adults. Pattern of use and effect on transfusion requirements. N Engl J Med 1986; 314: 1233-5.

5 Bourke DL, Smith TC. Estimating allowable hemodilution. Anesthesiology 1974; 41: 609-12.

6 Gross JB. Estimating allowable blood loss: corrected for dilution. Anesthesiology 1983; 58: 277-80.

7 Brecher ME, Rosenfeld M. Mathematical and computer modeling of acute normovolemic hemodilution. Transfusion 1994; 34: 176-9.

8 Widness JA, Kulhavy JC, Johnson KJ, et al. Clinical performance of an in-line point-of-care monitor in neonates. Pediatrics 2000; 106: 497-504.

9 Bailey PL, McJames SW, Cluff ML, et al. Evaluation in volunteers of the VIA V-ABG automated bedside blood gas, chemistry, and hematocrit monitor. J Clin Monit Comput 1998; 14: 339-46.

10 Kaye $A D$, Grogono $A W$. Fluid and electrolyte physiology. In: Miller RD (Ed.). Anesthesia, 5th ed. New York: Churchill Livingstone Inc.; 2000: 1586-612.

11 Corwin HL, Parsonnet KC, Gettinger A. RBC transfusion in the ICU. Is there a reason? Chest 1995; 108: 767-71.

12 Habn RG, Svensen C. Plasma dilution and the rate of infusion of Ringer's solution. Br J Anaesth 1997; 79: 64-7.

13 Smetannikov $\Upsilon$, Hopkins D. Intraoperative bleeding: a mathematical model for minimizing hemoglobin loss. Transfusion 1996; 36: 832-5.

14 Taylor PH, Heydinger DK, Bowers JD, Callendine GW $J r$. Evaluation of small acute blood loss in man. Am J Surg 1967; 114: 913-6. 